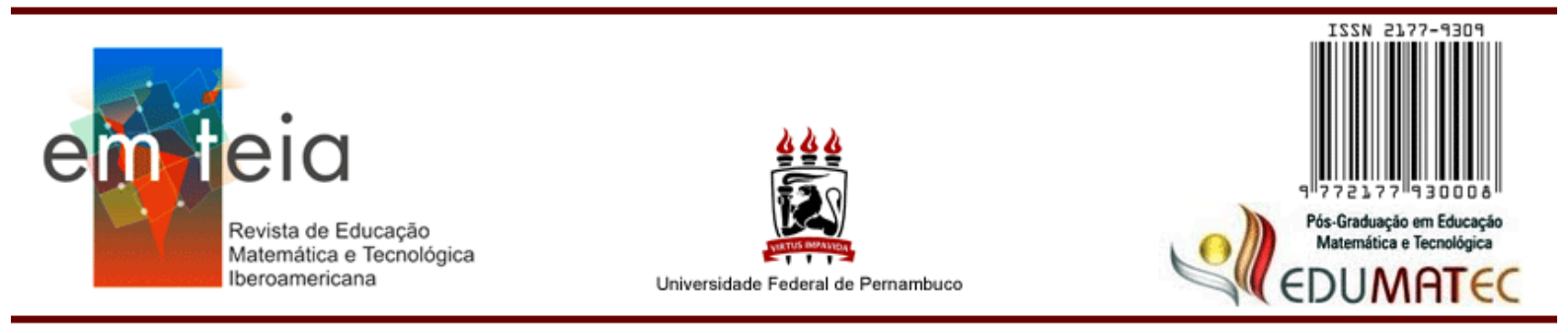

\title{
METODOLOGIA AUDIOVISUAL (PARTICIP)ATIVA NA FORMAÇÃO DE PROFESSORES: produção de videoaulas
}

Introdução

Elena Maria Mallmann

elena.ufsm@gmail.com

Lóren Kellen Carvalho Jorge elena.ufsm@gmail.com

Esse artigo sistematiza resultados de estudo sobre o potencial da produção de videoaulas como metodologia audiovisual (particip)ativa ${ }^{1}$ em cursos de formação de professores. Uma das principais características das metodologias (particip)ativas é envolver o estudante no processo construtivo da aprendizagem para que ele assuma um papel produtivo e tenha autoria no desenvolvimento do ensino-aprendizagem. O docente tem a função de orientar e conduzir as atividades, organizando conteúdos, enquanto o estudante trilha o seu caminho, partilhando espaços de produção ativa de recursos e realizando atividades.

Existe um vasto referencial teórico e prático de metodologias (particip)ativas. No entanto, os docentes têm autonomia didática para desenvolver técnicas autorais dando espaço para o estudante atuar como coprodutor na construção do conhecimento. Assim, apostamos que a produção de videoaulas se configura como uma metodologia em potencial para desenvolver contextos participativos e ativos na formação de professores.

As reflexões que acontecem no decorrer deste artigo centram-se nos resultados do Design-Based Research (DBR) realizado na disciplina "Pesquisa em Educação Profissional e Tecnológica A", do Programa Especial de Graduação - Formação de Professores para Educação Profissional, da Universidade Federal de Santa Maria (UFSM). O curso tem como propósito a

1 O termo (particip)ativa é de autoria própria e proveniente da junção das palavras "participativa" e "ativa". Optamos por utilizar essa composição de palavras, pois apesar da maioria das referências bibliográficas referentes ao tema utilizar o termo "ativa" acreditamos que ambas representam um conjunto de ações que desafiam o estudante a produzir conhecimento durante o processo ensino-aprendizagem. 
formação pedagógica de profissionais que possuem bacharelado para atuarem como professores na Educação Profissional e Técnica de Nível Médio da Educação Básica.

Durante toda a disciplina as atividades pedagógicas acoplaram os encontros presenciais com atividades extraclasse no Moodle. As atividades, tanto presenciais quanto a distância no curso, aumentam o espaço de autoria, autonomia e flexibilidade de tempo, espaço e interação, essenciais no contexto das metodologias (particip)ativas. Além disso, esse formato proporciona que o espaço da sala de aula seja melhor aproveitado para realizar reflexões, debates e para desenvolver habilidades práticas enquanto os estudos teóricos podem ser complementados por meio de atividades extraclasse individuais ou colaborativas.

A metodologia audiovisual (particip)ativa, com foco na produção de videoaulas, possibilitou abordar os conteúdos curriculares da disciplina com o trabalho contínuo presencial e a distância ao longo de todo semestre. A produção de videoaulas é um processo de autoria que proporciona envolvimento contínuo dos estudantes já que precisam estudar, sintetizar e desenvolver fluência no conteúdo e nas tecnologias para a produção da videoaula. Luiz e Sá (2016) acreditam que existe um potencial para a criação de novas metodologias de ensino. De acordo com os autores,

\footnotetext{
Com a presença das tecnologias digitais na sala de aula temos um grande potencial para o desenvolvimento de metodologias de ensino e atividades que colocam o aluno como sujeito ativo da construção do conhecimento e também no desenvolvimento de competências necessárias para a plena realização do cidadão do século XXI (2016, p. 29).
}

Os autores mencionam a importância dos estudantes desenvolverem competências "necessárias" diante dos desafios socioculturais e econômicos contemporâneos. Dessa maneira, proporcionar aos egressos do curso de Formação de Professores para Educação Profissional atividades teórico-práticas torna possível explorar os conteúdos curriculares de diversas formas, ampliando o caráter expositivo ou agrupado em seminários de sistematização. Essas atividades teórico-práticas fazem parte da metodologia (particip)ativa desenvolvida, pois os estudantes tiveram acesso a conceitos teóricos, pesquisa bibliográfica, artigos, materiais didáticos de autoria dos docentes, explanação em aula e também os encontros práticos em laboratório de informática.

Ademais, com o segmento audiovisual como recorte das pesquisas acopladas à docência, notamos a valorização da produção de conteúdo em formato de vídeo. Desta forma, 
consideramos necessário inserir essa possibilidade metodológica no contexto educacional específico dos cursos de formação pedagógica na universidade. Ao aprimorar metodologias (particip)ativas de produção hipermidiática em formatos audiovisuais, no ensino superior, é possível incrementar o processo ensino-aprendizagem mediado por tecnologias também na educação básica.

Com isso, podemos propor uma nova forma de trabalhar o recurso audiovisual das videoaulas em sala de aula, aplicar uma metodologia (partip)ativa e utilizar a produção de videoaulas com propósito voltado à construção curricular em contexto específico de formação de professores para educação profissional e tecnológica. Moran (2013, p. 56) afirma que "a linguagem audiovisual desenvolve múltiplas atitudes perceptivas". Dessa forma, os estudantes se envolvem e compreendem o material de diferentes maneiras. Para Barrére (2014, p. 80), videoaula significa:

[...] um vídeo que tem por finalidade auxiliar alguém a aprender alguma coisa independente da forma ou especificidade. Pode incorporar um caráter essencialmente pedagógico ou até aspectos mais tutoriais, como a utilização de um software ou a construção de algum artefato.

Barrére (2014) vê diferentes potencialidades nas videoaulas. O recurso audiovisual pode ser aplicado como: a) conteúdo único ou principal da disciplina; b) conteúdo de uma disciplina; c) conteúdo complementar de uma disciplina; d) opção para demonstrar algum conteúdo; e) atividade prática. Neste trabalho, as videoaulas apresentam potencial para serem exploradas como uma metodologia (particip)ativa promovendo a autoria e a colaboração entre os atores do ensino-aprendizagem.

As videoaulas são recursos educacionais que oferecem aos estudantes a possibilidade de estudar um conteúdo quantas vezes for necessário, com recurso de áudio ou legenda, animações, apoio textual e visual. Elas oferecem grande potencial para difusão do conhecimento, já que muitas pessoas podem ter acesso ao recurso ao mesmo tempo tanto offline quanto online. Além disso, o recurso aumenta a democratização do ensino e o acesso ao conhecimento, já que pode ser assistido com o auxílio de aparelhos diversos (celulares, computadores, tablets), por mais simplificados que sejam. Sanchez (2017) entende que o uso das videoaulas, aliado a outros recursos educacionais, pode ser uma ligação eficiente entre professores e estudantes. Além disso, a autora ressalta que este elo tende a se potencializar 
se o professor tiver um suporte tecnológico que possibilite autonomia para a produção das videoaulas.

Dessa forma, consideramos a produção de videoaula como uma metodologia audiovisual (particip)ativa, pois, ao proporcionar ao estudantes (que já são ou serão futuros professores) a formação e o espaço para autonomia e autoria, estamos possibilitando suporte tecnológico e pedagógico para os atores envolvidos no processo, que vão desenvolver e projetar em sala de aula o conhecimento construído. Assim, ao produzir videoaulas, o docente e o estudante agem ativamente, pois constroem de forma autoral o material utilizado nos espaços educacionais. Sanchez $(2017$, p. 11) menciona que

As variadas formas de se editar vídeos permitem que o professor integre seu material didático em slides e gráficos à sua fala, em momentos de narração de conceitos. É importante ressaltar que assistir a videoaulas não significa uma atitude passiva. Ao contrário, contribui para a disciplina do estudante, a qual já mencionamos, ao seu autodesenvolvimento e autogestão.

Partilhamos da mesma reflexão da autora, pois acreditamos que somente o ato de assistir videoaulas não significa passividade, porque, ao visualizar os recursos, os indivíduos estão envolvidos psicologicamente de alguma forma, mesmo não agindo de forma comportamental ativa. Exemplo disso é depois de uma explanação de uma videoaula os estudantes interagirem, questionarem, dialogarem sobre o recurso. Ser ativo não é apenas envolver fisicamente os estudantes de maneira diferente e participativa, mas sim submergir psicologicamente, de forma ativa, fazendo surgir dúvidas, questões, apontamentos, ao invés do simples aceite. Por isso é fundamental que as videoaulas, quando integradas como recursos, precisam estar acopladas a atividades de estudo que desafiem os estudantes na perspectiva da resolução de problemas.

No trabalho docente investigativo apoiado pela DBR, a produção de videoaulas emergiu tanto como atividade prática quanto conteúdo complementar da disciplina. Ou seja, o conteúdo curricular previsto no Projeto Pedagógico do Curso (PPC) foi totalmente contemplado permitindo, para além disso, ampliar a formação docente no desenvolvimento da Fluência Tecnológico-Pedagógica (FTP). No contexto de um curso de formação de professores, essa fluência não é somente de caráter tecnológico, mas também pedagógico, tanto pela matriz epistemológica quanto política. 
Desenvolver FTP no contorno das metodologias (particip)ativas, seja via produção de videoaulas ou qualquer outro recurso hipermidiático, é uma característica importante e imprescindível no contexto das tecnologias educacionais. $O$ desenvolvimento de capacidades necessárias para o exercício pleno da cidadania requer conhecimentos inerentes ao funcionamento e às potencialidades das tecnologias. Adquirir fluência não é somente saber usar, mas também saber criar, explorar as ferramentas tecnológicas para a produção autoral e compartilhar as produções com o maior número de pessoas. Por isso, a produção de videoaulas permite desenvolver e aprimorar paulatinamente FTP em cursos de formação de professores com propostas de metodologias (particip)ativas, pois promovem a ação do estudante, prezam pela autoria e pela autonomia do indivíduo. Para Schneider (2012, p. 80),

Ser fluente tecnologicamente significa conhecer e apropriar-se das ferramentas educacionais, seus princípios e aplicabilidade em diferentes soluções. Criar, corrigir, modificar interativamente diferentes ferramentas e artefatos, compartilhando novos conceitos, funções, programas e ideias.

A FTP exige dos indivíduos um aprendizado constante que é adquirido, recontextualizado e retemporalizado a todo instante. Ela é acionada quando precisamos potencializar a nossa capacidade de resolução de problemas gerando reflexões sobre tudo que é possível criar e compartilhar com as tecnologias contemporâneas (MALLMANN; SCHNEIDER; MAZZARDO, 2013). Desse modo, as metodologias (particip)ativas nos cursos de formação de professores implicam atenção redobrada para FTP. Participar ativamente da produção de conteúdos e os compartilhar de modo consciente e crítico na rede somente é possível se sabemos como as tecnologias funcionam, quais são os princípios e as políticas de privacidade, de segurança, de manutenção de software e hardware, exploração dos conteúdos de upload e download para fins econômicos, coleta e divulgação de informações pessoais etc.

Kafai e outros (1999) explicam a FTP baseados em três dimensões: habilidades contemporâneas, conceitos fundamentais e capacidades intelectuais. As habilidades contemporâneas vão além da teoria porque implicam uso, dizem respeito às operações necessárias para realizar qualquer atividade mediada pela tecnologia. Os conceitos fundamentais referem-se ao conhecimento teórico macro relacionado às tecnologias para compreender como elas funcionam, especialmente devido ao avanço da convergência das 
mídias. As capacidades intelectuais estão ligadas à reflexão, solução de problemas com base nas tecnologias com gerenciamento de tarefas e situações mais complexas que exigem avaliação e comunicação precisa. Schneider e outros (2012), com base nos estudos de Kafai e outros (1999), consideram essas três dimensões como níveis de fluência técnica, prática emancipatória, pois, "ser fluente é ser capaz de utilizar as tecnologias, desenvolver, compreender os conceitos básicos e estar sempre pronto a mudanças" (2012, p. 5).

Por isso, a produção de videoaulas como metodologia audiovisual (particip)ativa é de fato uma estratégia em potencial, pois alia a teoria (nível teórico possibilitado pelos conteúdos trabalhados na disciplina) à prática (nível emancipatório, pois coloca os estudantes como autores do processo de construção curricular no ensino-aprendizagem).

\section{Percurso Metodológico}

Neste capítulo, tratamos de uma proposta de metodologia (particip)ativa no âmbito da estruturação didática de uma disciplina de um curso de formação de professores. Os resultados em discussão são oriundos de estudos realizados com embasamento na tipologia de pesquisa Design-Based Research (DBR). As publicações sobre os princípios e as características ainda são incipientes no Brasil, mas, na literatura internacional, a DBR é fortemente indicada para projetos de pesquisa que tenham como temática a resolução de problemas mediada por tecnologias educacionais (PETERSON; HERRINGTON, 2005; DESIGNBASED RESEARCH COLLECTIVE, 2003). Wang e Hannafin (2005) dizem que, por ser sistemática e flexível, a DBR é potente para promover ciclos iterativos de design, desenvolvimento e implementação de novas soluções educacionais. Assim, o contexto em análise não trata apenas de uma aplicação metodológica, mas de um processo orientado por resultados de pesquisa durante a prática, para que a própria organização didático-metodológica pudesse ser ciclicamente aprimorada. Os dados foram produzidos na disciplina "Pesquisa em Educação Profissional e Tecnológica A", composta por 32 (trinta e dois) estudantes, de diferentes áreas de formação (bacharelado).

As estratégias organizativas da metodologia (particip)ativa envolveram atividades presenciais e extraclasse sistematizadas no Moodle institucional. Recursos educacionais como artigos e hipertextos de autoria dos professores foram inseridos para que a sala de aula fosse um espaço de debate e reflexão sobre as temáticas curriculares. A metodologia (particip)ativa 
com a produção de videoaulas contou com dois encontros práticos para capacitar os estudantes a desenvolverem FTP com software livre de captura de tela e organização didática dos conteúdos curriculares. Essa estratégia de metodologia (particip)ativa, apoiada na DBR, teve como base o design como forma de investigação, pois de acordo com Anderson e Shattuck (2012, p. 16),

\begin{abstract}
A DBR é uma metodologia criada por e para educadores que visa aumentar o impacto, a transferência e a tradução da pesquisa em educação para uma prática desenvolvida. Além disso, ela destaca a necessidade pela construção de teoria e desenvolvimento dos princípios de design que guiem, informem e melhorem tanto a prática quanto a pesquisa nos contextos educacionais (tradução nossa²).
\end{abstract}

Os ciclos interativos da DBR servem para aprimorar a: a) teoria e a prática; b) aplicação dos resultados obtidos na pesquisa; c) colaboração entre pesquisadores e participantes (MAZZARDO et al., 2016), elementos que são essenciais no quadro de um processo ensinoaprendizagem pautado em metodologias (particip)ativas. Dessa forma, a produção de videoaulas como metodologia (particip)ativa contemplou a dinâmica dos ciclos da DBR tornando possível criar teorias e desenvolver princípios de design para guiar e melhorar a prática e consequentemente a aprendizagem dos conteúdos.

A primeira das quatro fases da DBR é de identificação e análise de um problema. Analisamos que os estudantes já estavam adaptados a algumas metodologias ativas, como os seminários temáticos. No entanto, os trabalhos realizados no formato de seminários muitas vezes são repetitivos e exploram pouco a criatividade e autoria dos estudantes, já que eles nem sempre aproveitam outras formas de apresentação do conteúdo que não seja a explanação com apoio de slides. Assim, a produção de videoaulas foi uma proposta diferente para o ensino-aprendizagem e também de autoria, com exploração de diversos recursos de imagens, sons e animações. Esse foi o período destinado para o estudo detalhado dos conteúdos relacionados às temáticas estabelecidas dentro do programa da disciplina.

Na segunda fase da DBR, intitulada de desenvolvimento de soluções, o foco concentrou-se nos projetos e nas produções propriamente ditas, o que exigiu desenvolver e

\footnotetext{
${ }^{2}$ DBR is a methodology designed by and for educators that seeks to increase the impact, transfer, and translation of education research into improved practice. In addition, it stresses the need for theory building and the development of design principles that guide, inform, and improve both practice and research in educational contexts (2012, p. 16).
} 
aprimorar os princípios assinalados da FTP. Por isso, o redesign metodológico implicou a implementação de oficinas de captura de tela para a produção de videoaulas, com prioridade para softwares que pudessem ser manipulados no laboratório de informática da universidade. Com base em aplicações anteriores para outros públicos, o redesign permitiu que a oficina fosse planejada novamente com foco especial para o processo tecnológico-pedagógico em curso de formação de professores.

Na terceira fase, ocorreu a implementação da produção das videoaulas. Os estudantes tiveram espaço-tempo destinado especialmente para roteirização, organização, seleção de recursos de apoio, construção de slides, escrita de textos, testes e gravações de voz. Tudo isso ocorreu dentro da carga horária da disciplina com orientação e supervisão docente.

A proposta foi desenvolvida com o estabelecimento e acordo coletivo de critérios. Esses critérios preestabelecidos tornaram-se as categorias avaliativas dos resultados da atividade (particip)ativa: a) tempo médio de 10 minutos; b) licenciamento da videoaula no Creative Commons; c) inserção de créditos e referências de todos os recursos utilizados; d) apresentação de síntese do conteúdo; e) organização didático-metodológica da apresentação; f) publicação das videoaulas em fórum na disciplina no Moodle. Além destes critérios, o material produzido foi apresentado com destaques pontuais e explanações complementares dos estudantes, que precisavam apresentar uma discussão de trinta (30) minutos e todos os componentes do grupo deveriam contribuir com o debate acerca do tema apresentado e sobre a produção da videoaula.

Durante os encontros práticos, os estudantes conheceram o software livre Kazam, um programa que possibilita a captura em formato de imagens e vídeos, nas extensões de JPGEG, MP4, AVI e VP8. Apesar de ser indicado para a realização do trabalho, sua utilização não era obrigatória, uma vez que o propósito prioritário era o desenvolvimento de videoaulas autorais e colaborativas. Nesse caso, os condicionantes da fluência tecnológica dos estudantes não poderiam ser elementos impeditivos.

Apoiado na DBR, a coleta de dados para o quarto ciclo, avaliação e reflexão, se deu por meio da técnica de observação participante durante a produção das videoaulas, bem como no momento de apresentação do seminário temático, da análise das videoaulas produzidas pelos estudantes, debates em sala de aula e de questionário avaliativo. 


\section{Resultados em evidência}

Os temas para orientar as pesquisas bibliográficas, os estudos teóricos e a sistematização conceitual estiveram pautados no programa curricular da disciplina e encadeados com a lista de classificação de áreas do CNPq. Foram organizados sete grupos com os seguintes temas: 1) Formação de professores e Pesquisa em Educação; 2) Pesquisa em Educação Profissional e Tecnológica; 3) Etnografia; 4) Ética na Pesquisa em Educação; 5) Pesquisa-Ação; 6) Bases Teóricas da Pesquisa em Educação; 7) Estudo de Caso.

O primeiro grupo realizou uma síntese do conteúdo por tópicos e utilizou recursos visuais que exemplificaram o contexto. No entanto, o grupo não licenciou de forma aberta o produto e, assim, ele encontra-se protegido por direitos autorais, o que limita o reuso e prejudica a expansão da videoaula e do conhecimento contido nela. $\mathrm{O}$ grupo não atingiu a média de tempo esperada, totalizando apenas 4 minutos e 51 segundos. Também não inseriu os créditos e as referências usados. Já o segundo grupo teve como diferencial a utilização de uma vinheta de abertura e de finalização, no entanto, ambos os trechos escolhidos detinham direitos autorais, embora houvesse diversas orientações verbais e escritas durante as aulas para essas situações. Dessa forma, apesar de terem licenciado o produto, o uso de materiais com direitos autorais impede que ele possa ser reutilizado de forma aberta. Este grupo foi o que ultrapassou a média estipulada de tempo, totalizando 11 minutos e 59 segundos.

Os demais grupos atenderam todos os itens (critérios) solicitados, incluindo o licenciamento aberto e o tempo médio. $O$ terceiro grupo misturou o recurso de captura de tela com a gravação audiovisual de um integrante explicando o conteúdo. A técnica tornou o recurso dinâmico por mesclar mais de um estilo de captura audiovisual. Já o quarto grupo escolheu produzir uma videoaula tutorial, apresentando as plataformas que auxiliam pesquisadores na regulamentação de projetos de pesquisa. O grupo mostrou o processo na Plataforma Brasil. O exemplo dinamizou o assunto e o deixou mais prático e simplificado. 0 quinto grupo apresentou recursos visuais de imagens e ilustrações que auxiliaram quem assistia. O sexto grupo destacou-se por inserir plataforma do Youtube de forma autônoma destacando condições de FTP para além daqueles critérios estabelecidos no início da atividade. Foi o único grupo que apresentou ficha de créditos ao final da videoaula. Por fim, o sétimo grupo atendeu os requisitos de avaliação e também se destacou em termos de FTP e compartilhamento aberto por inserir de forma autônoma o recurso no Youtube. O grupo 
utilizou um recurso de apresentação online para a captura de telas e tornou a videoaula mais dinâmica.

Com base nas categorias de análise, os dois primeiros grupos, que também foram os primeiros a apresentar, foram os únicos que não atenderam totalmente os critérios, porque não tiveram a contribuição dos demais pares antes da finalização da videoaula. Embora todos os estudantes pudessem dialogar nas aulas e utilizar as ferramentas de comunicação do Moodle, percebemos que a produção se concentrou nos subgrupos. Desse modo, a proposta de um espaço específico para socialização dos produtos criados foi fundamental dentro do caminho metodológico particip(ativo) desenvolvido. A contribuição dos pares fez com que os demais grupos pudessem corrigir e/ou melhorar seus produtos antes da apresentação com base nas próprias considerações dos colegas. Como eram 7 grupos, dentro da carga horária de 30h, foi necessário destinar mais de um dia para as apresentações.

Com base na análise das videoaulas e da observação participante, também podemos ponderar que, mesmo com orientação e com apoio de laboratório e recursos humanos, somente um grupo utilizou o software livre apresentado nos encontros práticos. Este grupo foi o único que fez o trabalho em sua totalidade na sala de aula, ocupando de forma efetiva o espaço e a estrutura acadêmica. Dessa forma, concluímos que, mesmo oferecendo suporte, os estudantes apresentam resistência a softwares livres quando possuem situações-limite na fluência. Preferem utilizar ferramentas que já conhecem, pois sabem que os resultados podem comprometer a qualidade do produto final. Ficou evidente que o uso de metodologias (particip)ativas no contexto das tecnologias precisa estar acoplado ao desenvolvimento e aprimoramento da FTP, especialmente em cursos de formação de professores.

Para colaborar na análise de dados, acionados um questionário avaliativo, com o objetivo de avaliar a produção de videoaulas como metodologia (particip)ativa. Também questionamos os participantes sobre o potencial do recurso audiovisual acerca da autoria em rede. O questionário avaliativo foi estruturado em dez (10) perguntas, sendo nove (9) dissertativas e uma (1) de múltipla escolha.

Obtivemos o total de onze (11) participações, da turma de trinta e dois (32) estudantes. O questionário avaliativo era optativo e de carácter qualitativo não incidindo na nota. Apesar da baixa adesão, as respostas foram positivas para a pesquisa, pois a maioria dos estudantes 
se mostrou contente com a proposta e demonstrou estar aberta para novas práticas de metodologias.

Ao serem questionados se acreditavam que a produção de videoaulas poderia potencializar a autoria docente e discente, todos os respondentes afirmaram que sim. Alguns participantes justificaram argumentando que:

- A produção de videoaulas faz com que os assuntos sejam explorados de forma interativa, potencializando o aprendizado. $O$ autor de um vídeo agrega conhecimento sobre o tema;

- Sim, pois traz um diferencial para a sala de aula, tornando-as menos entediantes do que quando você passa um filme, por exemplo;

- Sim. É uma forma peculiar e de destaque docente e discente. Seu trabalho fica reconhecido e valorizado, sem falar que é inovador e dinâmico;

- Sim. Aprende-se produzindo e ensina-se através das apresentações. Com os colegas apresentadores podemos aprender outras técnicas de criação de vídeos;

- Sim, a produção de videoaulas desperta o interesse dos alunos pelos conteúdos e potencializa ao professor recursos pedagógicos.

A metodologia (particip)ativa de produção de videoaulas foi aprovada pelos estudantes, visto que todos os participantes mencionaram em uma das questões que fariam uso de videoaulas como proposta pedagógica em sala de aula. Os estudantes apontaram que consideram a videoaula uma "ferramenta valiosa e pouco utilizada", que ela "diversifica o aprendizado em sala de aula" e que "colaboram para o entendimento do assunto".

Em suma, ao longo dos ciclos iterativos da DBR, percebemos que os estudantes compreendem que a tecnologia pode potencializar o ensino-aprendizagem ao ser integrada com metodologias (particip)ativas, como a de produção de videoaulas.

\section{Considerações finais}

O estudo e as atividades realizadas com foco nas metodologias (particip)ativas audiovisual indicam que foi possível proporcionar uma nova forma metodológica de trabalhar o conteúdo curricular, com a produção de videoaulas. A maioria dos estudantes participou dos encontros práticos de forma ativa e apenas um número pequeno optou por usar os encontros práticos como uma maneira apenas de sanar dúvidas para realizar o trabalho extraclasse. 
Consideramos que os estudantes adquiriram níveis de fluência diferentes, conforme abordamos anteriormente: técnico, prático e emancipatório. Alguns apenas compreenderam o funcionamento do software apresentado, mas não evoluíram para os níveis prático e emancipatório. A atividade não esteve limitada ao uso ou não de determinado software e sim a que os estudantes realizassem produções em formato de videoaulas como processo de construção dos conhecimentos envolvidos no programa curricular da disciplina. Dessa forma, consideramos que os estudantes desenvolveram Fluência Tecnológico-Pedagógica (FTP) nas suas criações. A produção de videoaulas como metodologia (particip)ativa abriu espaço para a autoria e o protagonismo dos estudantes, deixando a disciplina mais reflexiva, ao invés de se limitar a um caráter instrumental sobre tipos de pesquisa, métodos de produção e análise de dados.

Nas apresentações dos produtos audiovisuais, os estudantes prestaram atenção aos recursos utilizados pelos colegas e puderam melhorar seus trabalhos e corrigir os problemas apontados nos demais trabalhos. Ao longo do andamento das práticas ativas envolvidas pelo recurso de videoaula, os estudantes compreenderam a importância dos itens solicitados para a produção. Ao fazerem a inserção de forma autônoma os dois grupos atentaram para também inserção da licença Creative Commons no Youtube, mesmo que o processo instrucional de como fazer o licenciamento na plataforma não tenha sido explanado durante os encontros. Esses grupos, além de terem compreendido os conceitos, desenvolveram FTP e conseguiram resolver outra questão que envolvia teoria e prática de forma autônoma e comprometida com a perspectiva dos Recursos Educacionais Abertos (REA).

Concluímos que a produção de videoaulas como metodologia (particip)ativa foi exitosa, porque os estudantes aprenderam com suas produções, foram autores durante todo processo ensino-aprendizagem, desenvolveram novas habilidades e melhoraram seus projetos com base na colaboração dos colegas. Além de tudo, dentro dessa proposta de metodologia (particip)ativa audiovisual, pudemos encorajar atividades colaborativas, comunicação multidirecional e avaliação entre pares.

\section{Referências}

ANDERSON, Terry; SHATTUCK, Julie. Design-Based Research: A Decade of Progress in Education Research? Educational Researcher, v. 41, n. 1, p. 16-25, 2012. Disponível em: http://journals.sagepub.com/doi/abs/10.3102/0013189X11428813. Acesso em: 18 jul. 2017. 
BARRÉRE, Eduardo. Videoaulas: aspectos técnicos, pedagógicos, aplicações e bricolagem. In: 3o Congresso Brasileiro de Informática na Educação, Dourados, MS, 03 a 06 de novembro de 2014. Disponível em: <www.brie.org/pub/index.php/pie/article/download/3154/2668>. Acesso em: 18 ago. 2017.

DESIGN-BASED RESEARCH COLLECTIVE. Design-based research: An emerging paradigm for educational inquiry. Educational Researcher, v. 32, n. 1, p. 5-8, 2003. DOI:

10.3102/0013189X032001005. Recuperado de

http://www.designbasedresearch.org/reppubs/DBRC2003.pdf.

KAFAI, Yasmin et al. Being fluent with information technology. Washington D.C: National Academy Press, 1999. Disponível em: <https://www.nap.edu/catalog/6482/being-fluentwith-information-technology>. Acesso em: 14 fev. 2018.

LUIZ, Learcino; SÁ, Ricardo de. Aprendizagem com dispositivos móveis: reflexões epistemológicas e práticas no ensino de matemática. In: RAABE, André et al. Educação Criativa: Multiplicando experiências para a aprendizagem. 2016. Disponível em: <https://www.researchgate.net/profile/Alex_Gomes2/publication/308566653_Educacao_Cr iativa_Multiplicando_experiencias_para_a_aprendizagem/links/57e71a0b08aed7fe466a152 5/Educacao-Criativa-Multiplicando-experiencias-para-a-aprendizagem.pdf>. Acesso em: 10 fev. 2018.

MALLMANN, Elena; SCHNEIDER, Daniele; MAZZARDO, Mara. Fluência TecnológicoPedagógica (FTP) dos Tutores. Renote, v. 11, n. 3, dezembro, 2013. Disponível em: <http://www.seer.ufrgs.br/index.php/renote/article/view/44468/28213>. Acesso em: 13 fev. 2018.

MAZZARDO, Mara Denize et al. Design-Based Research: desafios nos contextos escolares. 2016. Disponível em:

<http://proceedings.ciaiq.org/index.php/ciaiq2016/article/viewFile/691/679>. Acesso em: 13 fev. 2018.

MORAN, José Manuel. Ensino e aprendizagem inovadores com apoio de novas tecnologias. In: MORAN, José Manuel; BEHRENS, Marilda Aparecida; MASETTO, Marcos T. Novas tecnologias e mediação pedagógica. Campinas, SP: Papirus, 2013.

PETERSON, R.; HERRINGTON, J. The state of the art of design-based research. In: The World Conference on E-Learning in Corporate, Government, Healthcare, and Higher Education. Vancouver, Canadá. 2005. Recuperado de http://ro.uow.edu.au/cgi/viewcontent. cgi ?article $=1060 \&$ context=edupapers.

SANCHEZ, Tatiana. Videoaula atrelada a outros recursos: realismo e maleabilidade. In: SILVA, Andreza (Org.). Demandas para a Educação a Distância no Brasil no Século XXI. Ponta Grossa, PR: Athena, 2017. p. 112-119. 
SCHNEIDER, Daniele. Prática dialógico-problematizadora dos tutores na UAB/UFSM: fluência tecnológica no Moodle. 2012. 203 p. Dissertação (Mestrado em Educação) Universidade Federal de Santa Maria, Santa Maria, 2012. Disponível em: <http://repositorio.ufsm.br/handle/1/7000 >. Acesso em: 10 fev. 2018.

SCHNEIDER, Daniele e outros. Fluência tecnológica dos tutores em ambientes virtuais. Renote, v. 10, n. 1, julho, 2012. Disponível em:

<http://seer.ufrgs.br/renote/article/viewFile/30821/19193 >. Acesso em: 13 fev. 2018.

WANG, Feng; HANNAFIN, Michael. Design-based Research and Technology-Enhanced Learning Environments. ETR\&D, v. 53, n. 4, pp. 5-23. 2005. Recuperado de https://ideascale.com/userimages/sub-1/898000/panel_upload_12279/30221206.pdf. Acesso em: 18 mar. 2018. 